\title{
Changes in Onset and Withdrawal of the East Asian Summer Rainy Season by Multi-Model Global Warming Experiments
}

\author{
Akio KITOH and Takao UCHIYAMA \\ Meteorological Research Institute, Tsukuba, Japan \\ (Manuscript received 27 April 2005, in final form 15 November 2005)
}

\begin{abstract}
Baiu-Changma-Meiyu is a rainy period in early summer over East Asia (Japan, Korea and China) and its variability and change is one of the major focus in climate change projections in these areas. We analyze the changes in intensity and duration of Baiu-Changma-Meiyu rain by global warming using daily precipitation data of fifteen coupled atmosphere-ocean general circulation model (AOGCM) simulations under the SRES A1B scenario at the end of the twenty-first century. It is revealed that a delay in early summer rain withdrawal over the region extending from Taiwan, Ryukyu Islands to the south of Japan is contrasted with an earlier withdrawal over the Yangtze Basin, although the latter is not significant due to inconsistent sign of changes among the models. Higher mean sea-level pressure anomalies in the tropical western Pacific in the future may be related to these late withdrawals. Changes in onset dates are relatively less compared to those in withdrawal dates.
\end{abstract}

\section{Introduction}

It is expected that anthropogenic global warming, due to increasing atmospheric concentrations of greenhouse gases, will result in large changes in Asian climate, including changes in surface temperature and changes in the monsoon intensity and duration over South Asia, Southeast Asia and East Asia, and even in the relationship between the El NiñoSouthern Oscillation (ENSO) and monsoon. An increase of the greenhouse gases will lead to increased surface air temperature and precipitation in the global mean sense, but its geographical distribution is not easy to project, in particular with respect to precipitation. IPCC (2001), which assessed consistency of regional and seasonal mean precipitation change due

Corresponding author: Akio Kitoh, Climate Research Department, Meteorological Research Institute, 1-1 Nagamine, Tsukuba, Ibaraki, 305-0052 Japan.

E-mail: kitoh@mri-jma.go.jp

(C) 2006, Meteorological Society of Japan to global warming among several coupled atmosphere-ocean general circulation models (AOGCMs), reported that most tropical areas will have increased mean precipitation, and most of the subtropical areas will have decreased mean precipitation at the end of the twenty-first century due to anthropogenic influence. An increase in summertime precipitation in East Asia, and South Asia, and a mean El Niño-like response in the tropical Pacific, with a corresponding eastward shift of precipitation are also noted.

It has been known that most of GCMs have difficulty in simulating the distribution and the annual cycle of the precipitation in the East Asian monsoon region (e.g., Kang et al. 2002). One of the most distinct characteristics in East Asia is the early summer rainfall, i.e. Meiyu in China, Baiu in Japan and Changma in Korea, which is associated with a narrow rain band with a stationary Meiyu/Baiu front (Tao and Chen 1987; Ninomiya and Murakami 1987). Its typical season is May to July in China, June to early July in Japan, and July 
in Korea. Meiyu/Baiu/Changma rainfall is important for water resource including agriculture, but heavy rainfall often results in disasters in East Asian countries, and thus it is important to simulate accurately with climate models. Although earlier model studies showed insufficient representation of this rain belt with an ordinary climate model, current models show some ability of medium resolution models to simulate the Baiu front precipitation in certain periods of the model integration (T42L52 CCSR/NIES AGCM, Ninomiya et al. 2002) or even in the climatological mean fields (T42L30 MRI-CGCM2, Rajendran et al. 2004; Kitoh 2004).

Recently, various modeling groups have performed new simulations including the historical run (twentieth century experiments; 20C3M) and future climate simulations based on a diverse set of scenarios. Those model data are collected and archived at the Program for Climate Model Diagnosis and Intercomparison (PCMDI), and have been analyzed in various aspects by many scientists. In this paper, we analyze the changes in intensity and period of the East Asian early summer rainy season at the end of the twenty-first century, using daily precipitation data of fifteen AOGCMs for the twentieth century experiment (20C3M), and the future climate projections based on SRES A1B scenario (IPCC 2000). The analysis method using multiple GCMs (multi-model ensemble), is effective for the improvement of the projection due to reduction of biases and uncertainties of an individual model (Giorgi and Mearns 2002; Min et al. 2004). We use multiple-model ensemble (MME) means by weighting each model by its skill against observations.

\section{Data}

We use daily precipitation data for 20 years at the present-day (1981-2000) of the 20C3M simulation and at the end of the twenty-first century (2081-2100) under the SRES A1B scenario simulation. Models used are: CCSM3, CGCM3.1(T47), CGCM3.1(T63), CNRM-CM3, CSIRO-Mk3.0, ECHAM5/MPI-OM, FGOALSg1.0, GFDL-CM2.0, GFDL-CM2.1, GISS-AOM, GISS-ER, INM-CM3.0, MIROC3.2(hires), MIROC3.2(medres) and MRI-CGCM2.3.2. See Table 1 for model name, originating model group and atmospheric horizontal resolution. Details on each model are available from http://wwwpcmdi.llnl.gov/ipcc/about_ipcc.php. Only one member (the first member) is used, even if multi-member data are available for some models to equally treat each model. Twenty-year mean five-day averaged precipitation (pentad

Table 1. List of AOGCMs used in this study. See http://www-pcmdi.llnl.gov/ipcc/about_ ipcc.php for more details.

\begin{tabular}{llc}
\hline Model I.D. & \multicolumn{1}{c}{ Modeling Group, Country } & Resolution \\
\hline CCSM3 & National Center for Atmospheric Research, USA & T85 \\
CGCM3.1(T47) & Canadian Centre for Climate Modelling \& Analysis, Canada & T47 \\
CGCM3.1(T63) & As above & T63 \\
CNRM-CM3 & Meteo-France/Centre National de Recherches & TL63 \\
& Meteorologiques, France & T63 \\
CSIRO-Mk3.0 & CSIRO Atmospheric Research, Australia & T63 \\
ECHAM5/MPI-OM & Max Planck Institute for Meteorology, Germany & T42 \\
FGOALS-g1.0 & LASG/Institute of Atmospheric Physics, China & $2 \times 2.5$ \\
GFDL-CM2.0 & Geophysical Fluid Dynamics Laboratory, USA & $2 \times 2.5$ \\
GFDL-CM2.1 & As above & $3 \times 4$ \\
GISS-AOM & NASA/Goddard Institute for Space Studies, USA & $4 \times 5$ \\
GISS-ER & As above & $4 \times 5$ \\
INM-CM3.0 & Institute for Numerical Mathematics, Russia & T106 \\
MIROC3.2(hires) & Center for Climate System Research (University of Tokyo), & \\
& National Institute for Environmental Studies and Frontier & T42 \\
MIROC3.2(medres) & Research Center for Global Change (JAMSTEC), Japan & T42 \\
MRI-CGCM2.3.2 & As above & Meteorological Research Institute, Japan \\
\hline
\end{tabular}


Table 2. The standard deviation ratio (SDR), pattern correlation coefficient (R) with two observations and skill score (S) for the East Asian precipitation from fifteen models and four MMEs. SS is an average of four skill scores. MME15 denotes a simple average of 15 models. MME15w denotes a skill-weighted average of 15 models.

\begin{tabular}{|c|c|c|c|c|c|c|c|c|c|c|c|c|c|}
\hline \multirow[b]{3}{*}{ Model } & \multicolumn{6}{|c|}{ JJA x-y map (40-160 E 20 S-50 N) } & \multicolumn{6}{|c|}{$\begin{array}{c}\text { Jan-Dec t-y map } \\
(120-140 \text { E } 20 \mathrm{~S}-50 \mathrm{~N})\end{array}$} & \multirow{3}{*}{$\frac{\text { Mean }}{\text { SS }}$} \\
\hline & \multicolumn{3}{|c|}{ CMAP } & \multicolumn{3}{|c|}{ GPCP } & \multicolumn{3}{|c|}{ CMAP } & \multicolumn{3}{|c|}{ GPCP } & \\
\hline & SDR & $\mathrm{R}$ & $\mathrm{S}$ & SDR & $\mathrm{R}$ & $\mathrm{S}$ & SDR & $\mathrm{R}$ & $\mathrm{S}$ & SDR & $\mathrm{R}$ & $\mathrm{S}$ & \\
\hline$[3$ & & 0 & 0 & 9 & 0.757 & 0 & $=9$ & 0.718 & 0.519 & $J 2$ & 0.700 & & 0.507 \\
\hline CGCM3.1( & 907 & 0.863 & 0.746 & 1.345 & 0.822 & 0.631 & 1.159 & 0.843 & 0.705 & 1.895 & 0.791 & 0.439 & 0.630 \\
\hline CGCM3.1(T63) & 906 & 0.873 & 0.761 & 1.343 & 0.837 & 0.654 & 1.147 & 0.815 & 0.666 & 1.875 & 0.771 & 0.424 & 0.626 \\
\hline CNRM-CM3 & 549 & 0.746 & 0.413 & 0.813 & 0.708 & 0.509 & 0.781 & 0.701 & 0.492 & 1.277 & 0.682 & 0.472 & 0.472 \\
\hline CSIRO-Mk3.0 & 640 & 0.836 & 0.585 & 0.948 & 0.827 & 0.694 & 0.934 & 0.793 & 0.642 & 1.527 & 0.753 & 0.496 & 0.604 \\
\hline ECHAM5/MPI-OM & & 0.817 & & & & & & 0.841 & 0.626 & 2.382 & 0.800 & & 0.504 \\
\hline FGOALS-g1.0 & 0.493 & 0.690 & 0.321 & 0.732 & 0.640 & 0.410 & 0.665 & 0.708 & 0.452 & 1.087 & 0.718 & 0.540 & 0.431 \\
\hline GFDL-CM2.0 & 969 & 0.802 & 0.658 & 1.436 & 0.828 & 0.613 & 1.466 & 0.813 & 0.585 & 2.397 & 0.776 & 0.314 & 0.543 \\
\hline GFDL-C & 000 & 0.855 & 0.741 & 1.482 & 0.849 & 0.628 & 1.545 & 0.810 & 0.558 & 2.526 & 0.787 & 0.299 & 0.557 \\
\hline GISS-AOM & 778 & 0.773 & 0.581 & 1.154 & 0.762 & 0.591 & 0.871 & 0.728 & 0.546 & 1.424 & 0.665 & 0.425 & 0.538 \\
\hline & & & & & & & & 0.754 & 0.590 & 1.727 & 0.734 & 0.425 & 0.481 \\
\hline INM-CM3.0 & 0.726 & 0.598 & 0.369 & 1.077 & 0.587 & 0.394 & 0.761 & 0.636 & 0.415 & 1.244 & 0.600 & 0.391 & 0.392 \\
\hline MIROC3.2(hires) & 0.927 & 0.671 & 0.485 & 1.374 & 0.737 & 0.515 & 1.029 & 0.726 & 0.554 & 1.681 & 0.750 & 0.452 & 0.502 \\
\hline MIROC3.2(medres) & 0.876 & 0.722 & 0.540 & 1.299 & 0.746 & 0.542 & 0.762 & 0.702 & 0.487 & 1.245 & 0.691 & 0.488 & 0.514 \\
\hline MRI-CGCM2.3.2 & 1.020 & 0.802 & 0.658 & 1.512 & 0.737 & 0.481 & 1.052 & 0.859 & 0.744 & 1.719 & 0.808 & 0.505 & 0.597 \\
\hline & 020 & 0.900 & & 0.927 & 0.889 & 0.191 & & 0.869 & & & 0.837 & & 0.709 \\
\hline MME15w & 0.664 & 0.905 & 0.700 & 0.943 & 0.891 & 0.797 & 0.843 & 0.874 & 0.749 & 1.283 & 0.837 & 0.670 & 0.729 \\
\hline
\end{tabular}

climatology) is first calculated for each model for each period. Then these model climatology data are interpolated into the common 2.5 degree by 2.5 degree horizontal grids. Corresponding monthly mean data for surface air temperature, and mean sea-level pressure, are also utilized.

For evaluation of the model precipitation, two observed rainfall dataset are used: the CPC Merged Analysis of Precipitation (CMAP) (Xie and Arkin 1997), and the Global Precipitation Climatology Project (GPCP) Version 1 Pentad Mean Precipitation Dataset (Xie et al. 2003). For both the datasets, a 25-year (19792003) pentad-mean climatology is used.

\section{Results}

\subsection{Weighted multi-model ensemble}

Before making multi-model ensembles, the performance of the present climate simulations are evaluated with respect to the CMAP and the GPCP datasets. Spatial variance and pattern correlation coefficients are calculated between the model and each of the observations.
Regions selected are: (1) the longitude-latitude cross-section of the Northern Hemisphere summer June-August (JJA) mean precipitation over $40^{\circ} \mathrm{E}-180^{\circ} \mathrm{E}, 20^{\circ} \mathrm{S}-50^{\circ} \mathrm{N}$ (Fig. 1a), and (2) the time-latitude cross-section of the $120^{\circ} \mathrm{E}-$ $140^{\circ} \mathrm{E}$ averaged pentad precipitation between $20^{\circ} \mathrm{S}-50^{\circ} \mathrm{N}$ (Fig. 2a). Ratio of standard deviations (SDR) and pattern correlation coefficients (R) for each model against two observations, and for each region, is shown in Table 2. The skill score as suggested by Taylor (2001)

$$
\mathrm{S}=4(1+\mathrm{R})^{4} /\left[(\mathrm{SDR}+1 / \mathrm{SDR})^{2}(1+\mathrm{R})^{4}\right]
$$

is introduced here.

For the JJA mean precipitation field, the skill score $\mathrm{S}$ varies from 0.321 to 0.761 against the CMAP data, and from 0.394 to 0.694 against the GPCP data. The model that has the best skill against the CMAP does not necessarily show the best skill for the GPCP. Larger SDR values for GPCP than those for CMAP reflect the fact that the GPCP data has smaller magnitude of precipitation values for almost the entire area evaluated. Two multi-model en- 
semble means are calculated. One is a simple average of all fifteen models, and is denoted as "MME15". The skill score of MME15 is 0.658 for CMAP, and 0.791 for GPCP. The other is a weighted average of fifteen models using the skill score S, and is denoted "MME15w". The skill score of MME15w is better than that of MME15, particularly for the case against CMAP. Only three models are better than MME15w in skill score against CMAP, and MME15w against GPCP outstands any single model's skill score.

The skill score for the time-latitude cross section of the $120^{\circ} \mathrm{E}-140^{\circ} \mathrm{E}$ averaged pentad precipitation varies from 0.415 to 0.744 against the CMAP data, and from 0.299 to 0.540 against the GPCP data for each model, but MME15w is 0.749 and 0.670 , respectively, and is better than any single model result.

The average skill score (SS) is defined as the mean of four $\mathrm{S}$ for each model and MMEs. The SS varies from 0.392 to the best model 0.630. In the following analyses, SS is used to weight each model data to make multi-model ensembles, and those results are simply called MME15w hereafter.

\subsection{Spatial distribution of precipitation}

Figures $1 \mathrm{a}$ and $1 \mathrm{~b}$ show the Asian sector horizontal distribution of the JJA mean precipitation for the CMAP observations (Xie and Arkin 1997), and the fifteen models weighted ensemble mean (MME15w). Multi-model ensemble reproduces well the observed features, such as precipitation maxima over the western coast of India, the Bay of Bengal, the South China Sea and the Philippine Sea. A rain belt over southwestern Japan (Baiu rain band) can also be discerned from the multi-model simulations. Models overestimated precipitation along the southern periphery of the Tibetan Plateau. This feature is seen in most of the models, and may be related to model's failure to depict topography, due to coarse horizontal resolution. Kobayashi and Sugi (2004) demonstrate that increasing horizontal resolution can alleviate this deficiency using the JMA atmospheric GCM.

IPCC (2001) reported consistent JJA precipitation increase over South Asia and East Asia, for both the SRES A2 and B2 scenarios, but no change for $\mathrm{A} 2$ and inconsistent response for $\mathrm{B} 2$ (a) Observations (JJA)
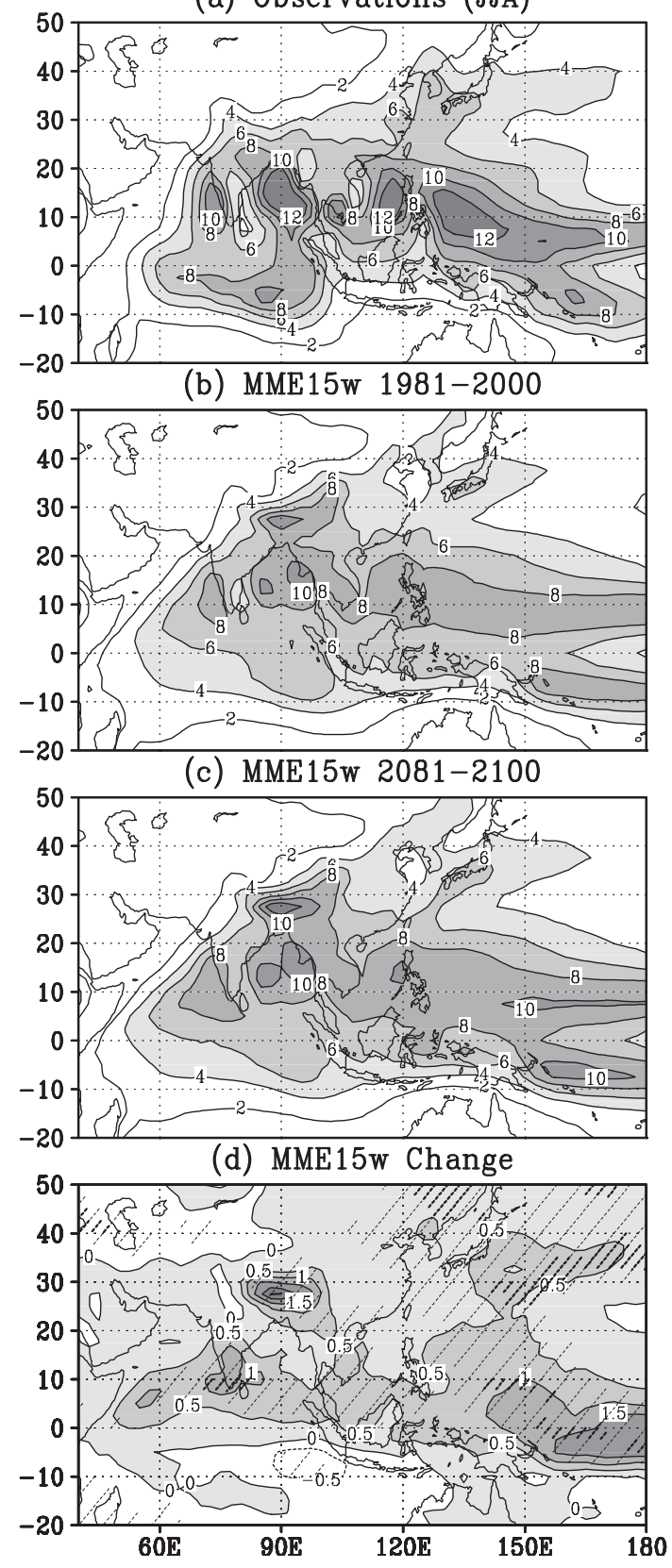

Fig. 1. Northern Hemisphere summer (JJA) mean precipitation $\left(\mathrm{mm} \mathrm{day}^{-1}\right.$ ). (a) Observations (Xie and Arkin 1997). (b) Multi-model ensembles (MME15w) for the present day (1981-2000) of the 20C3M experiments. (c) As in (b) except for the 2081-2100 of the SRES A1B experiments. (d) Differences between (c) and (b). Light and heavy slant lines denote areas where the difference is larger than 0.5 and 1.0 times of intermodel standard deviation, respectively. 
over Southeast Asia. Lal and Harasawa (2001), based on four relatively skillful model results, obtained a general increase in precipitation over most of Asia, except for a decrease in summertime precipitation over Central Asia. Based on multi-model ensembles, Min et al. (2004) obtained increased East Asia precipitation in the warmer season (April to September).

For the MME15w, the JJA mean precipitation for 2081-2100 of the SRES A1B simulations, and the changes are shown in Figs. 1c and $1 \mathrm{~d}$, respectively. In order to show statistical significance of multi-model ensemble mean changes, grid points where the change is larger than 0.5 and 1.0 times of intermodel standard deviation of the changes, are marked by light and heavy slant lines, respectively, in Fig. 1d. It is shown that projected JJA precipitation increases over South Asia, East Asia as well as Southeast Asia. Precipitation increase is also large over the central equatorial Pacific, suggesting an El Niño-like mean climate change by global warming, which is noted by the previous model results (IPCC 2001). Precipitation changes are small in some part of South Asia, such as western coast of Indochina peninsula, and around the Philippines. It is noted that negative precipitation anomalies prevail over the South Indian Ocean. Increase in precipitation is found over East Asia, particularly around Japan, which makes the Baiu rain band more visible from Taiwan northeastward to Japan (Fig. 1c).

Figures $2 \mathrm{a}$ and $2 \mathrm{~b}$ show the time-latitude cross-section of pentad mean precipitation averaged for $120^{\circ} \mathrm{E}-140^{\circ} \mathrm{E}$ for the CMAP observations and the multi-model ensembles, respectively. The observation shows a clear beginning of heavy rain at mid-May around $25^{\circ} \mathrm{N}$, and a subsequent northward migration towards $35^{\circ} \mathrm{N}$ at the end of July, corresponding to Baiu rain band and its seasonal migration. The multimodel ensemble mean shows the tropical heavy precipitation area following the seasonal cycle, and some flavor of reproducing spring rain along $30^{\circ} \mathrm{N}-40^{\circ} \mathrm{N}$ and its maximum in June. There also is a hint of less precipitation area between the Baiu rainy area and tropical rain area over the Philippine Sea.

The time-latitude cross-section for the 20812100 simulation, and the changes from the present-day simulation for MME15w are shown (a) Observation
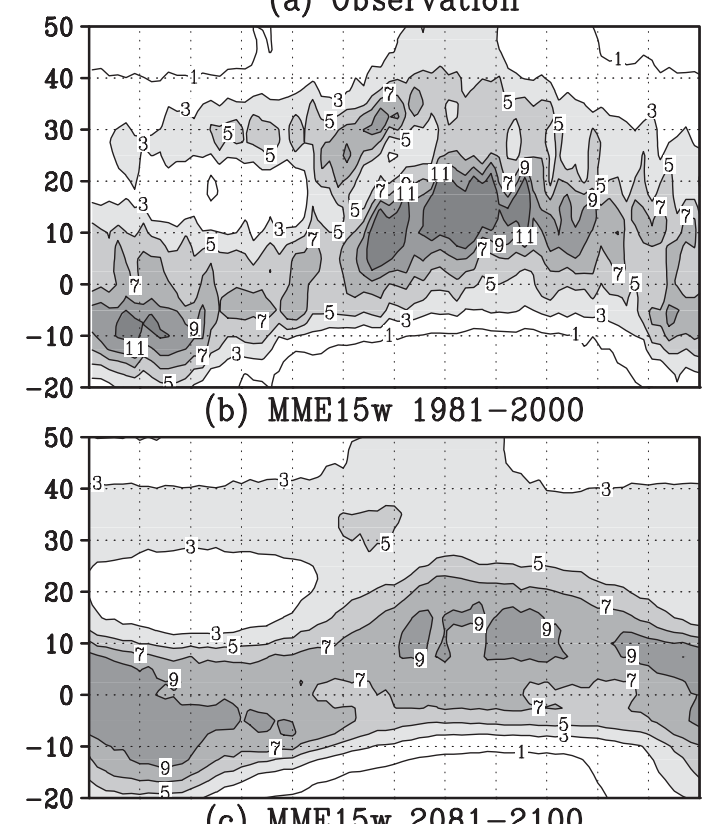

(c) MME15w 2081-2100

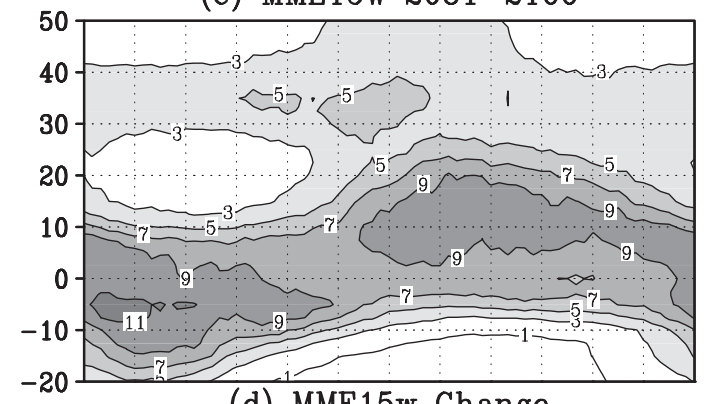

(d) MME15w Change

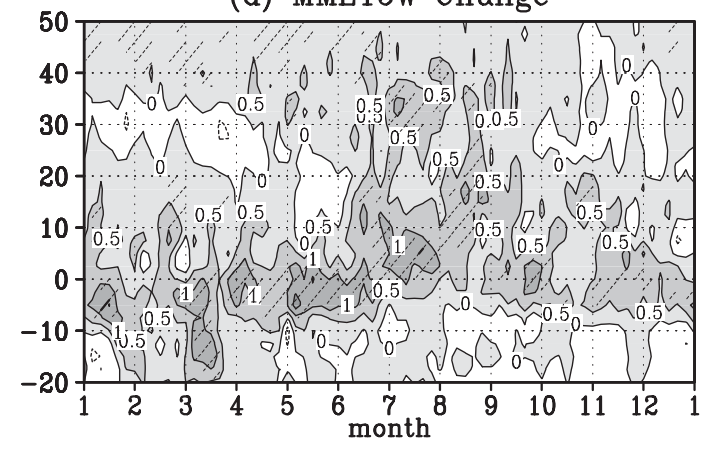

Fig. 2. Time-latitude section of precipitation $\left(\mathrm{mm} \mathrm{day}^{-1}\right)$ averaged for $120^{\circ} \mathrm{E}-$ $140^{\circ}$ E. (a) Observations (Xie and Arkin 1997). (b) Multi-model ensembles (MME15w) for the present day (19812000) of the 20C3M experiments. (c) As in (b) except for the 2081-2100 of the SRES A1B experiments. (d) Differences between (c) and (b). Light and heavy slant lines denote areas where the difference is larger than 0.5 and 1.0 times of intermodel standard deviation, respectively. 
in Figs. 2c and 2d, respectively. The difference map is somewhat noisy, but clearly shows increased precipitation over the tropical rain area throughout the year, and the summer rain band around $30^{\circ} \mathrm{N}$ from June to August. It is noted that a contrast between less precipitation between $10^{\circ} \mathrm{N}$ and $20^{\circ} \mathrm{N}$ before June and subsequent increase becomes more distinct by global warming.

\subsection{Onset and withdrawal dates of rainy season}

Thin lines in Fig. 3a denote the smoothed annual cycle of pentad precipitation averaged for the region around Japan $\left(120^{\circ} \mathrm{E}-140^{\circ} \mathrm{E}, 25^{\circ} \mathrm{N}-\right.$ $35^{\circ} \mathrm{N}$ ) for the present-day climatology of each model. Here smoothed annual cycle is defined as the sum of the annual mean and the first 12 harmonics. The multi-model ensemble mean (thick solid line), and the CMAP observations (thick dashed line with open square) are also shown. Model scatter (standard deviation among models) is large, and ranges between $0.8 \mathrm{~mm} \mathrm{day}{ }^{-1}$ (late winter) and $1.9 \mathrm{~mm}$ day $^{-1}$ (early summer). Therefore observed precipitation annual cycle is almost within model precipitation envelops (mean plus or minus one standard deviation) except for early June, late August and late September when model precipitation is significantly less than the observations. As is seen in Figs. 1 and 2, models underestimate summer precipitation maximum over the Philippine Sea, hence underestimate northward rainfall propagation by intraseasonal oscillation. Inability of simulating strong tropical cyclones, which contribute to larger part of rainfall amount in this season, may also be a reason. Multi-model ensemble mean value is less than the observations during spring, summer and fall, and is larger than the observations during winter. In June, MME15w has underestimated the observations about $2 \mathrm{~mm} \mathrm{day}^{-1}$.

Figure $3 \mathrm{~b}$ compares the MME15w presentday, and the end-of-the twenty-first century annual cycle of precipitation around Japan. An increase in precipitation is seen almost all year round except for early winter and March. Precipitation in the future scenario simulations is larger than the present-day simulations, more than $0.3 \mathrm{~mm}$ day $^{-1}$ from June through early September, with the maximum difference oc- (a) Models vs Observations
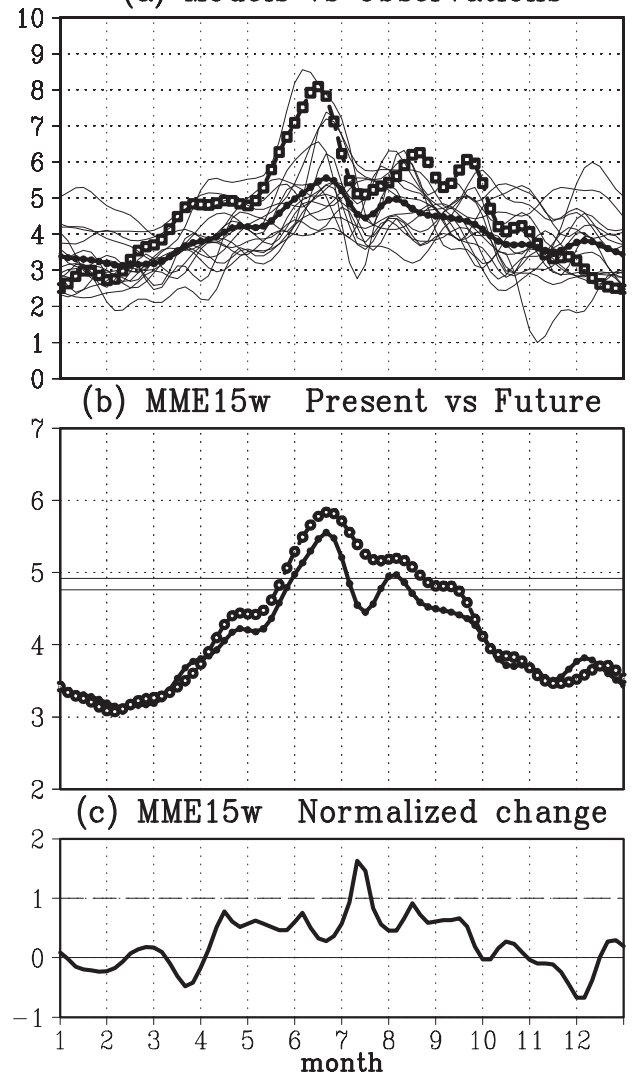

Fig. 3. (a) Annual time series of pentad mean precipitation averaged for $120^{\circ} \mathrm{E}-140^{\circ} \mathrm{E}, \quad 25^{\circ} \mathrm{N}-35^{\circ} \mathrm{N}$ for each model climatology for 1981-2000 of the 20C3M experiments (thin lines), multimodel ensemble mean (MME15w: thick solid line) and the observations (thick dashed line with open square). (b) Thick solid line is the same as in (a), while dashed line with open circle denotes the value for the 2081-2100 of the SRES A1B experiments. (c) Normalized changes of the MME15w pentad mean precipitation.

curring in July. As will be imagined by large scatter among models (Fig. 3a), both the present and future ensemble means (MME15w) are well within an envelope of each model lines. In order to estimate robustness of the change, the difference of regional mean precipitation is divided by the intermodel standard deviation of the differences (Fig. 3c). This normalized difference exceeds one during only the 2 nd and the 
3rd pentads of July. Therefore, an increased precipitation in this region by multi-model ensemble is robust only in the high summer season.

Several ways are proposed to define onset and withdrawal dates of monsoons. For example, based on the relative climatological pentad mean rainfall, which is the difference between the climatological pentad mean rainfall for May-September and January mean rainfall, Wang and Linho (2002) defined the onset as the Julian pentad when the relative climatological pentad mean rainfall exceeds $5 \mathrm{~mm}$ day $^{-1}$, and the withdrawal pentad when it drops below $5 \mathrm{~mm}$ day $^{-1}$. Zeng and Lu (2004) proposed the onset and withdrawal dates when a normalized (between 0 and 1) index, such as precipitable water, exceeding a threshold value of 0.618 (the Golden Ratio), and obtained a reasonable global-scale picture. Many attempts have been continuing for studies of interannual variability and predictability, but there will be no unified and perfect index of monsoon onset and withdrawal for global change studies as the mean value, as well as the seasonality, might change by global warming.

Here we use an index similar to Zeng and $\mathrm{Lu}$ (2004), but applying for precipitation. For each 2.5 degree by 2.5 degree grid points, a smoothed annual cycle of pentad precipitation is first obtained by calculating the sum of the annual mean and the first 12 harmonics for the present-day and future MME15w model climatology. Then a normalized pentad precipitation index (NPI) is defined:

$$
\mathrm{NPI}=\left(P-P_{\min }\right) /\left(P_{\max }-P_{\min }\right)
$$

where $P$ is the smoothed pentad precipitation climatology, and $P_{\max }$ and $P_{\min }$ are the annual maximum and minimum $P$ at each grid point, respectively. We define the Asian summer monsoon region where $P_{\max }$ appears between March and September. The onset date is then defined as the Julian pentad when NPI exceeds a threshold value (0.618), and the withdrawal date as the pentad when NPI drops below this value first after the onset. For example, two thin solid lines in Fig. 3b correspond to the threshold values in the present and future for the area averaged pentad mean precipitation, respectively (the upper line is for the future). In this area averaged case, the onset occurs at pentad 30 in both cases, but the withdrawal occurs at pentad 39 (early July) in the present and at pentad 48 (late August) in the future. The withdrawal becomes very late in the future, due to increased precipitation in July. In the following, this method is applied at each grid point. The criteria for this specific threshold value has no objective reason, but actually, the following results do not change much if the threshold value is varied for about $20 \%$.

Figure 4 shows the horizontal distributions of the onset dates of the summer rainy season, based on the climatological pentad mean precipitation for the CMAP observations, MME15w for the present day (1981-2000), MME15w for the 2081-2100 of the SRES A1B experiment, and its changes. A spatial ninepoint smooth filter is applied to the pentad mean precipitation data before calculating the onset dates to minimize small-scale noise. In the observations, the earliest beginning of the rainy season is noted over southern China already in March (Julian pentad less than 18). This is known as the spring persistent rains (Tian and Yasunari 1998). The onset takes place earliest over the region extending from South China through the Indochina peninsula. Afterwards the onset progresses northwestward towards India, and also northward over East Asia, where it begins in late May over Taiwan and the Ryukyu Islands and in late June in Kyusyu. The onset is very late over the western North Pacific. These characteristics are generally well reproduced in the multimodel ensembles (Fig. 4b), although the onset is too early over eastern China, the onset is late over the Indochina peninsula, and a northward progression of onset over eastern China is not well seen in the model. This may be related to a more northward shifted spring persistent rain area in the models. The onset date of Baiu simulated by the MME15w is around the end of May or early June, which is close to the observed onset timing.

Figure $4 \mathrm{~d}$ shows the change in onset dates from the present to the future climate by the multi-model ensemble mean. It is shown that the change in onset dates at the end of the twenty-first century, is relatively small and within two pentads over most of the regions, with slightly earlier onset in India and western China, and later onset over the Indochina pen- 
(a) Observations

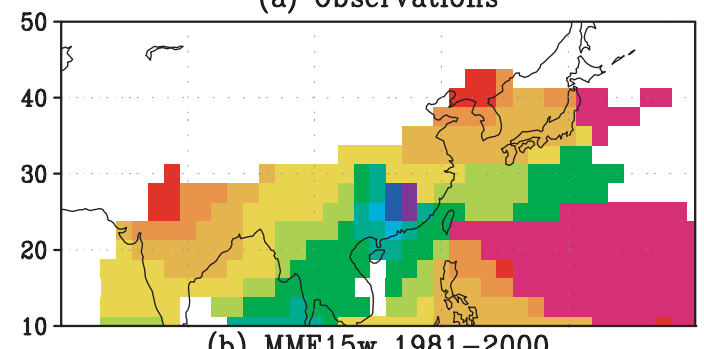

(b) MME15w 1981-2000

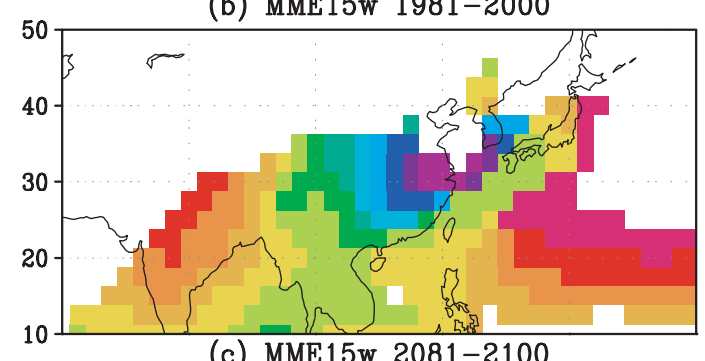

(c) MME15w 2081-2100

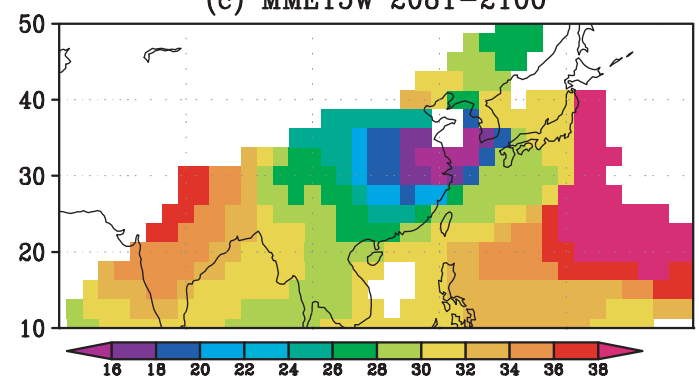

(d) MME15w Change

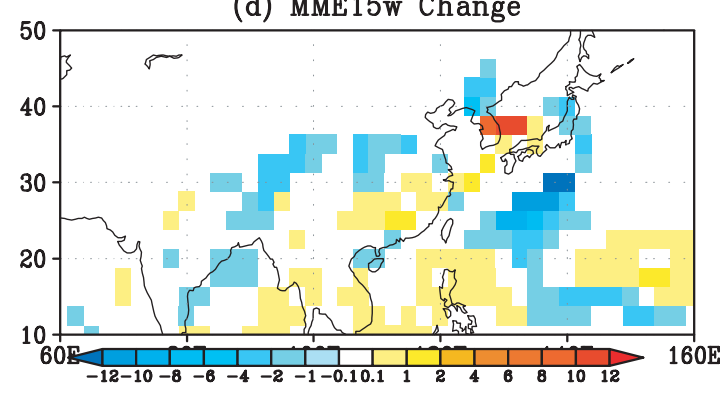

(e) MME15w Change Consistency

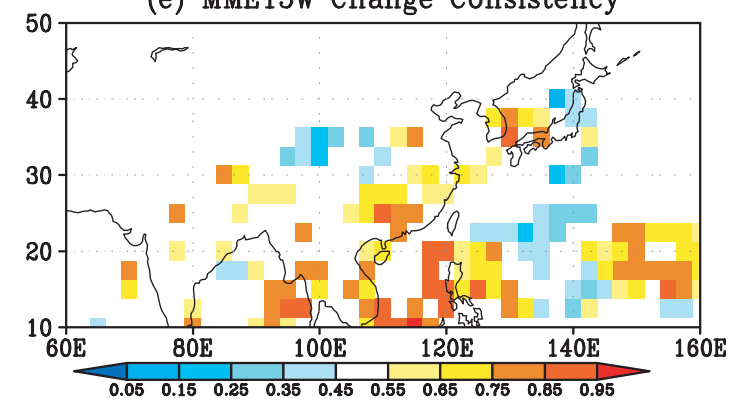

insula, and a region extending from southern China to Japan. There are some spotty regions with large changes over the ocean to the south of Japan (early onset) and around Korea (late onset). To investigate its robustness, consistency ratio among models is calculated (Fig. $4 \mathrm{e})$. Here the consistency is defined as a fraction of the number of models with positive change in onset dates: that is, the value is 1.0 if all models have projected delayed onset, and is 0.0 if all models have projected early onset in the future compared to the present. From Fig. $4 \mathrm{e}$, most models show delayed onset over the Indochina peninsula, the South China Sea, the southern part of China and southern Korea to the western Japan region. However, most of large changes to the south of Japan are not robust, implying that a few models' large changes have affected the result.

Figure 5 shows the withdrawal dates of the summer rainy season. The observations (Fig. 5a) show the earliest withdrawal of late June over the region extending from southern China to the south of Japan. The withdrawal progresses in time toward northward and southward from this latitude band. It is mid-July over Japan. This is a consistent feature with that found by Wang and LinHo (2002). The multi-model ensemble mean (Fig. 5b) well captures the observed characteristics, except for the western tropical Pacific where the withdrawal date by MME15w delays compared to the observations. Over the Baiu region, the models show an early July withdrawal to the south of Japan, and a mid-July withdrawal over central Japan.

At the end of the twenty-first century, the withdrawal date clearly delays over South Asia from India through the Indochina peninsula,

Fig. 4. Onset dates (Julian pentad) of the summer rainy season based on the climatological pentad mean precipitation. (a) Observations. (b) Multi-model ensembles (MME15w) for the present day (1981-2000) of the 20C3M experiments. (c) As in (b) except for the 2081-2100 of the SRES A1B experiments. (d) Differences between (c) and (b). (e) Fraction of model numbers with positive difference of onset dates from the present to the future. 
(a) Observations

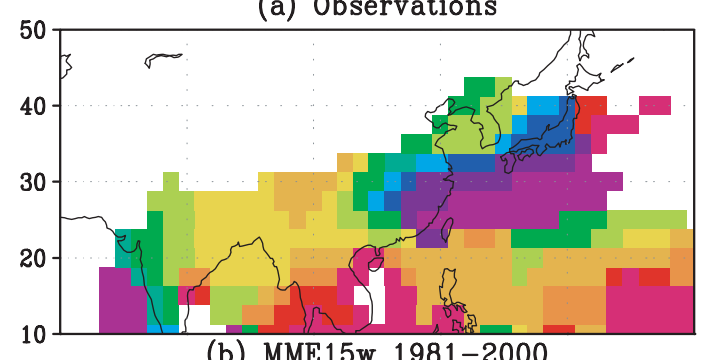

(b) MME15w 1981-2000

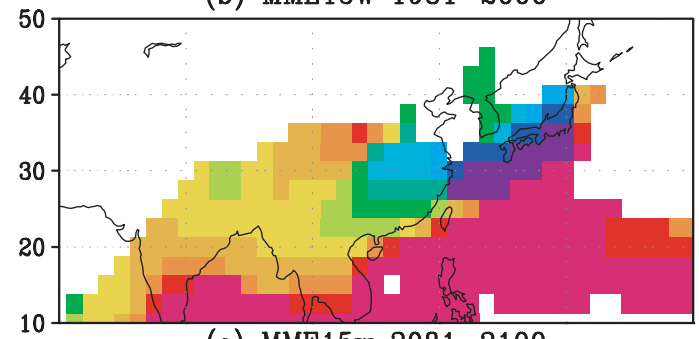

(c) MME15w 2081-2100

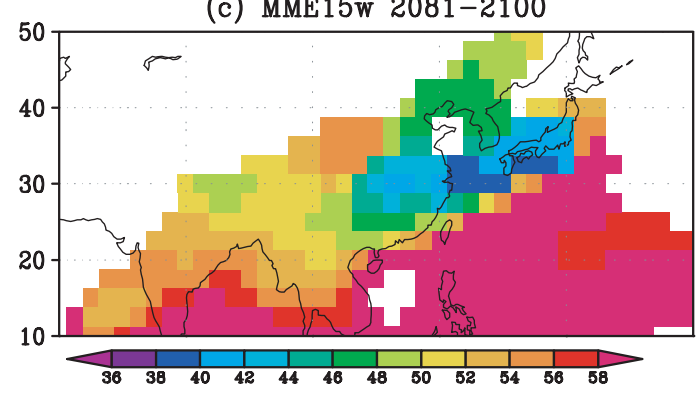

(d) MME15w Change

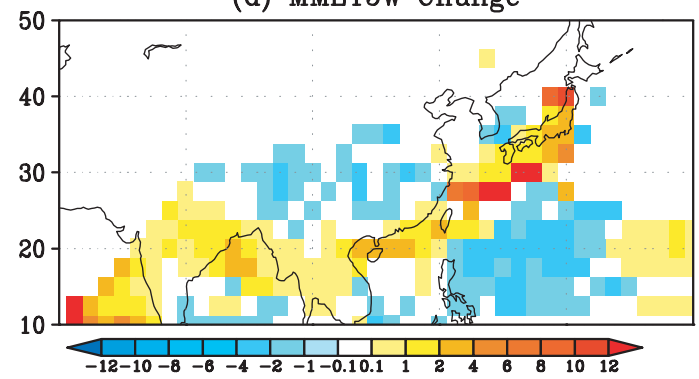

(e) MME15w Change Consistency

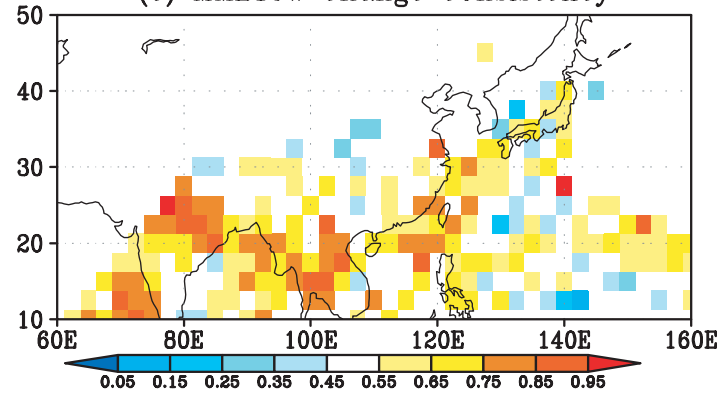

Fig. 5. As in Fig. 4 except for the withdrawal dates of the rainy season. and also over southern China, Taiwan, the Ryukyu Islands and mainland Japan. An early withdrawal can be seen over China, the Philippines Sea and the western Pacific region. Over India, it is about two pentads delay, while it is about three pentads delay over the Arabian Sea and the Bay of Bengal. Larger delay can be seen over the Baiu region from Taiwan, the Ryukyu Islands to the south of Japan, where more than one month delay of rainy season withdrawal is seen. However, by judging from inter-model consistency of sign in the changes (Fig. 5e), late withdrawal is robust over the region from the Arabian Sea to the Indochina peninsula, and the region from the Philippines, Taiwan and the East China Sea. As is shown in Fig. 3, these regions experience large increase in precipitation throughout the summer season by extending the rainy season from only early summer in the present-day case to the whole summer season in the warming climate. Over the Japanese Islands and the surroundings, there are some grid points with late withdrawal. Most of these grid points agree in its sign of the late withdrawal particularly over the Ryukyu Islands, but a few grid points in the vicinity of the Honshu Island do not, which suggests that it is difficult to make a clear assessment there. It is also noted that an early withdrawal over the western subtropical Pacific region and northern China is not consistent between the models.

\section{Discussion and conclusions}

We analyzed the changes in the Asian summer rainy season at the end of the twenty-first century by global warming using daily precipitation data of fifteen AOGCM simulations under the SRES A1B scenario. The multi-model ensemble mean is calculated based on their skill to reproduce the present-day climate compared to two observational data. Model ensemble mean reveals increased JJA precipitation over Asia, especially over the regions of South Asia, East Asia, as well as Southeast Asia with little increase over the Philippines and the surroundings. It is revealed that a delay in Baiu rain withdrawal around Japan is contrasted with an earlier withdrawal in Meiyu rain over southern China, although the latter is not significant due to inconsistent sign of changes among the models. Changes in onset dates are 
relatively less compared to those in withdrawal dates.

In order to see if there are systematic changes in circulation fields, the JJA mean surface air temperature, and mean sea-level pressure changes, are calculated between the 2081-2100 of the SRES A1B experiments, and the 1981-2000 of the 20C3M experiments by MME15w (Figs. 6a and 6b). Model uncertainty is also estimated by comparing the ensemble mean changes and the model scatter (intermodel standard deviation of the changes). For the surface air temperature, the changes exceed inter-model standard deviation everywhere, and thus not shown in the figure for brevity. The summertime surface air temperature changes are positive everywhere due to global warming, but reveal larger warming over subtropical land regions such as Middle East, western China and central USA. Over the tropical oceans, changes are smaller but there tends to be a maximum in the central equatorial Pacific region east of the dateline. Positive sea-level pressure anomalies are noted over South Asia and the maritime continent area in the tropics, while negative mean sealevel pressure anomalies prevail over the western Eurasian continent. Also noted there is a relatively lower pressure zone over the mid Pacific to the east of Japan, and positive anomalies over the Gulf of Alaska. The tendency for sea level pressure to become high in the region south of $30^{\circ} \mathrm{N}$ and become low in a $40^{\circ}-50^{\circ} \mathrm{N}$ belt, and the strengthening and southward movement of the Pacific anticyclone has been already noted in GCM (Kitoh et al. 1997) and RCM (Kato et al. 2001) experiments.

Uchiyama and Kitoh (2004) revealed that the global warming response by the MRI-CGCM2 SRES A2 scenario experiment is very similar to the anomalies in model El Niño years, and suggested that the delay of Baiu withdrawal is related to the changes in large scale circulation associated with El Niño-like changes in mean tropical climate. This feature is not so significant by the multi-model ensemble means, although the existence of the largest surface air temperature changes to the east of the dateline and more robust positive mean sea-level pressure changes in the tropical western Pacific than in the eastern Pacific suggests a hint toward multi-model El Niño-like signals. These (a) Tsa JJA MME15w Change

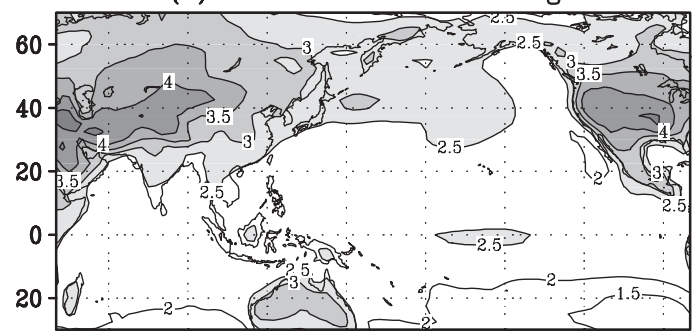

(b) Psl JJA MME15w Change

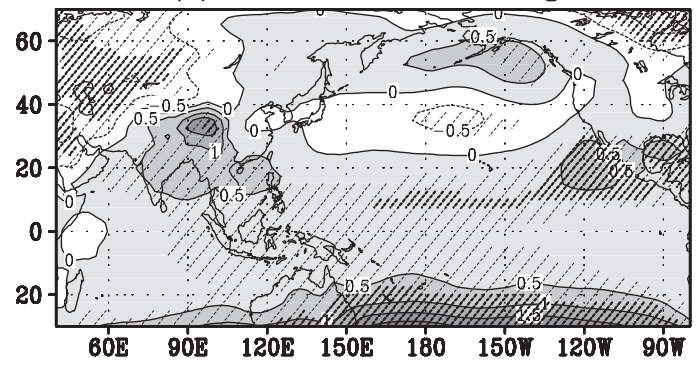

(c) Psl [120E-180E] MME15w Change

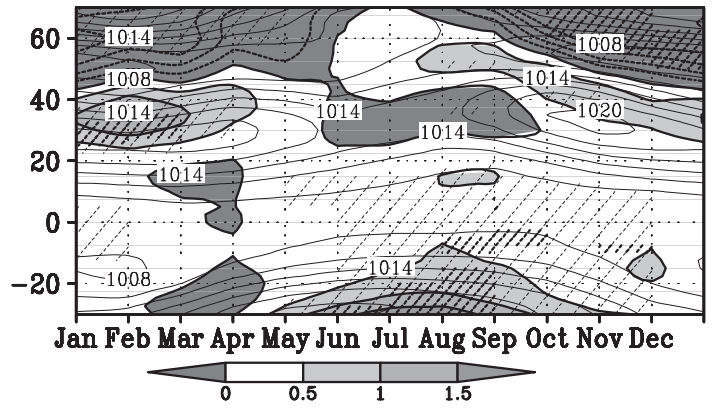

Fig. 6. Multi-model ensemble (MME15w) JJA mean differences in (a) surface air temperature and (b) mean sea-level pressure between the 2081-2100 of the SRES A1B experiments and the 19812000 of the 20C3M experiments. The contour interval is (a) $0.5 \mathrm{~K}$ and (b) $0.5 \mathrm{hPa}$. (c) Time-latitude section of mean sea-level pressure averaged for $120^{\circ} \mathrm{E}-180^{\circ} \mathrm{E}$. Thin lines are for the present-day. Solid lines with shading denote the difference between the 2081-2100 of the SRES A1B experiments and the 1981-2000 of the 20C3M experiments. Light and heavy slant lines in (b) and (c) denote areas where the difference is larger than 0.5 and 1.0 times of intermodel standard deviation, respectively. 
circulation anomalies can be effective to transport moisture from the low-latitudes to the Baiu-region to bring more precipitation there. The relationship between El Niño-like response and East Asian climate changes by global warming should be investigated further.

Figure $6 \mathrm{c}$ shows the time-latitude crosssection of mean sea-level pressure changes averaged for $120^{\circ} \mathrm{E}-180^{\circ} \mathrm{E}$ for the multi-model ensembles (MME15w) superimposed on the present-day simulations. In winter a northsouth dipole pattern with negative sea-level pressure anomalies in high-latitudes, contrasted with positive anomalies in midlatitudes is noted. This corresponds to a poleward shift of the Aleutian low and subtropical anticyclone system associated with a positive phase of the Northern Hemisphere annular mode. Only in summer (June through September) negative sea-level pressure anomalies appear around $40^{\circ} \mathrm{N}$ with high pressures to the north $\left(55^{\circ} \mathrm{N}\right)$ and over the southern oceans. Some part of the northern anomaly may correspond to the intensified Okhotsk High that is responsible to cool and wet conditions in Japan, due to a northeasterly flow from cold oceans, while the southern anomaly may correspond to El Niño-like tropical mean climate response. However, these circulation anomalies are not significant, and thus further elaboration is needed.

In this paper, we defined the onset and withdrawal dates of the summer rainy season as the normalized pentad precipitation exceeds a critical value of 0.618 and drops below that value, respectively. We applied this method on the climatological precipitation seasonal cycle. Another method would be to define the onset and withdrawal dates from individual years, and then take the averages. These could bring in different results, and thus the sensitivity on the method should be explored. Uchiyama and Kitoh (2004) applied an index similar to Wang and LinHo (2002) to the MRI-CGCM2 data and obtained a consistent result to this paper that the onset date does not change very much, but withdrawal date was clearly delayed near Japan. A use of the relative climatological pentad mean rainfall of Wang and LinHo (2002) sometimes makes a large part of Asia an undefined area because of model biases such as less summer rainfall or larger winter rainfall than the observations. Naturally, many other indices can be defined and application of such should be pursued.

\section{Acknowledgments}

We acknowledge the international modeling groups for providing their data for analysis, the Program for Climate Model Diagnosis and Intercomparison (PCMDI) for collecting and archiving the model data, the JSC/CLIVAR Working Group on Coupled Modelling (WGCM) and their Coupled Model Intercomparison Project (CMIP) and Climate Simulation Panel for organizing the model data analysis activity, and the IPCC WG1 TSU for technical support. The IPCC Data Archive at Lawrence Livermore National Laboratory is supported by the Office of Science, U.S. Department of Energy. Acknowledgment is extended to anonymous reviewers for comments and to D. Nohara for data handling.

\section{References}

Giorgi, F. and L.O. Mearns, 2002: Calculation of average, uncertainty range, and reliability of regional climate changes from AOGCM simulations via the "Reliability Ensemble Average" (REA) method. J. Climate, 15, 1141-1158.

IPCC, 2000: Special Report on Emissions Scenarios. Nakicenovic, N. and R. Swart (eds.), Cambridge University Press, 612pp.

IPCC, 2001: Climate Change 2001: The Scientific Basis. Contribution of Working Group I to the Third Assessment Report of the Intergovernmental Panel on Climate Change. Houghton, J.T. et al. (eds.), Cambridge University Press, 881pp.

Kang, I.-S. and co-authors, 2002: Intercomparison of the climatological variations of Asian summer monsoon precipitation simulated by 10 GCMs. Clim. Dyn., 19, 383-395.

Kato, H., K. Nishizawa, H. Hirakuchi, S. Kadokura, N. Oshima, and F. Giorgi, 2001: Performance of RegCM2.5/NCAR-CSM nested system for the simulation of climate change in East Asia caused by global warming. J. Meteor. Soc. Japan, 79, 99-121.

Kitoh, A., 2004: Effect of mountain uplift on East Asian summer climate investigated by a coupled atmosphere-ocean model. J. Climate, 17, 783-802.

, S. Yukimoto, A. Noda, and T. Motoi, 1997: Simulated changes in the Asian summer monsoon at times of increased atmospheric $\mathrm{CO}_{2} . \mathrm{J}$. Meteor. Soc. Japan, 75, 1019-1031. 
Kobayashi, C. and M. Sugi, 2004: Impact of horizontal resolution on the simulation of the Asian summer monsoon and tropical cyclones in the JMA global model. Clim. Dyn., 23, 165-176.

Lal, M. and H. Harasawa, 2001: Future climate change scenarios for Asia as inferred from selected coupled atmosphere-ocean global climate models. J. Meteor. Soc. Japan, 79, 219227.

Min, S.-K., E.-H. Park, and W.-T. Kwon, 2004: Future projections of East Asian climate change from multi-AOGCM ensembles of IPCC SRES scenario simulations. J. Meteor. Soc. Japan, 82, 1187-1211.

Ninomiya, K. and T. Murakami, 1987: The early summer rainy season (Baiu) over Japan. In: Monsoon Meteorology, C.-P. Chang and T.N. Krishnamurti (Ed.), Oxford Univ. Press, 93121.

, T. Nishimura, W. Ohfuchi, T. Suzuki, and S. Matsumura, 2002: Features of the Baiu front simulated in an AGCM (T42L52). J. Meteor. Soc. Japan, 80, 697-716.

Rajendran, K., A. Kitoh, and S. Yukimoto, 2004: South and East Asian summer monsoon climate and variation in MRI coupled model (MRI-CGCM2). J. Climate, 17, 763-782.

Tao, S. and L. Chen, 1987: A review of recent research on the East Asian summer monsoon in China. In: Monsoon Meteorology, C.-P. Chang and T.N. Krishnamurti (Ed.), Oxford Univ. Press, 60-92.

Taylor, K.E., 2001: Summarizing multiple aspects of model performance in a single diagram. J. Geophys. Res., 106, 7183-7192.

Tian, S.-F. and T. Yasunari, 1998: Climatological aspects and mechanism of spring persistent rains over Central China. J. Meteor. Soc. Japan, 76, 57-71.

Uchiyama, T. and A. Kitoh, 2004: Changes in BaiuChangma-Meiyu rain by global warming in MRI-CGCM. Proceedings of the International Conference on High-Impact Weather and Climate, March 22-24, 2004, Seoul, Korea, 218221.

Wang, B. and LinHo, 2002: Rainy season of the Asian-Pacific summer monsoon. J. Climate, 15, 386-398.

Xie, P. and P.A. Arkin, 1997: Global precipitation: A 17-year monthly analysis based on gauge observation, satellite estimates, and numerical model outputs. Bull. Amer. Meteor. Soc., 78, 2539-2558. and co-authors, 2003: GPCP Pentad Precipitation Analyses: An experimental dataset based on gauge observations and satellite estimates. J. Climate, 16, 2197-2213.

Zeng, X. and E. Lu, 2004: Globally unified monsoon onset and retreat indexes. J. Climate, 17, 2241-2248. 